\title{
Bacterial outer membrane vesicles and vaccine applications
}

\section{Reinaldo Acevedo ${ }^{1}$ *, Sonsire Fernández ${ }^{1}$, Caridad Zayas ${ }^{1}$, Armando Acosta ${ }^{1}$, Maria Elena Sarmiento ${ }^{1}$, Valerie A. Ferro ${ }^{2}$, Einar Rosenqvist ${ }^{3}$, Concepcion Campa' ${ }^{1}$, Daniel Cardoso ${ }^{1}$, Luis Garcia ${ }^{1}$ and Jose Luis Perez ${ }^{1}$}

1 Finlay Institute, Havana, Cuba

2 Strathclyde Institute of Pharmacy and Biomedical Science, Strathclyde University, Glasgow, UK

${ }^{3}$ Norwegian Institute of Public Health, Oslo, Norway

Edited by:

Virgil Schijns, Wageningen University, Netherlands

Reviewed by:

Scott D. Gray-Owen, University of Toronto, Canada

Fabio Bagnoli, Novartis Vaccines, Italy

*Correspondence:

Reinaldo Acevedo, Finlay Institute, Calle 17 esquina 198, Reparto

Siboney, Playa, La Habana 11600,

Cuba

e-mail: racevedo@finlay.edu.cu
Vaccines based on outer membrane vesicles (OMV) were developed more than 20 years ago against Neisseria meningitidis serogroup B. These nano-sized structures exhibit remarkable potential for immunomodulation of immune responses and delivery of meningococcal antigens or unrelated antigens incorporated into the vesicle structure. This paper reviews different applications in OMV Research and Development (R\&D) and provides examples of OMV developed and evaluated at the Finlay Institute in Cuba. A Good Manufacturing Practice (GMP) process was developed at the Finlay Institute to produce OMV from $N$. meningitidis serogroup $B\left(\mathrm{dOMV}_{\mathrm{B}}\right)$ using detergent extraction. Subsequently, OMV from $N$. meningitidis, serogroup $A\left(d O M V_{A}\right)$, serogroup $W\left(d O M V_{W}\right)$, and serogroup $X\left(d O M V_{X}\right)$ were obtained using this process. More recently, the extraction process has also been applied effectively for obtaining OMV on a research scale from Vibrio cholerae $\left(\mathrm{dOMV}_{\mathrm{C}}\right)$, Bordetella pertussis $\left(\mathrm{dOMV}_{\mathrm{BP}}\right)$, Mycobacterium smegmatis $\left(\mathrm{dOMV}_{\mathrm{SM}}\right)$, and $\mathrm{BCG}$ $\left(\mathrm{dOMV} \mathrm{V}_{\mathrm{BCG}}\right)$. The immunogenicity of the OMV has been evaluated for specific antibody induction, and together with functional bactericidal and challenge assays in mice has shown their protective potential. $\mathrm{dOMV}_{\mathrm{B}}$ has been evaluated with non-neisserial antigens, including with a herpes virus type 2 glycoprotein, ovalbumin, and allergens. In conclusion, OMV are proving to be more versatile than first conceived and remain an important technology for development of vaccine candidates.

Keywords: outer membrane vesicles, vaccines, proteoliposomes, adjuvant, Neisseria meningitidis, Vibrio cholerae, Bordetella pertussis, Mycobacterium tuberculosis

\section{INTRODUCTION}

Vesicles derived from pathogens have been used for a long time in the development of immunogenic vaccine candidates against the respective organisms from which the vesicles have been obtained. Proteoliposomes, outer membrane vesicles (OMV), proteasomes (1), and very small size proteoliposomes (2) are examples of the different approaches of vesicle formulations obtained from microorganisms. Currently, licensed vaccines based on OMV use detergent extraction to obtain dOMV from Gram negative bacteria (3). In addition, it is possible to obtain OMV by inducing the release of "blebs" or native OMV (nOMV) from bacteria (3). A drawback of this latter method is that the resulting vesicles contain a high amount of lipopolysaccharide (LPS), which is very toxic (4). Therefore, several strategies are under evaluation to produce nOMV from mutant strains containing detoxified LPS (5).

Various infectious diseases [such as tuberculosis (TB) and meningitis] and including enteric diseases (such as cholera, salmonellosis, and shigellosis) remain a health problem in children and young adults (6). No vaccines have been developed against the responsible pathogens and the OMV strategy represents a feasible opportunity to address this. OMV are at the interface between traditional and new methods of vaccine production. Antigens and immune stimulator molecules from OMV are extracted from the pathogen and purified in proteolipidic vesicles, a reason for also calling OMV proteoliposomes. Another approach is to use purified molecules from bacteria and inserting them into lipidic nanovesicles or adding any other components to the formulation. Therefore, several research groups have developed structures like proteasomes, which combine Neisseria meningitidis protein aggregates with LPS from Shigella flexneri (1) or very small size proteoliposomes, which combine OMV, also from N. meningitidis, with the ganglioside GM3 more frequently associated with tumor cells (2). The main goal of these nanoparticles or vesicles is to present or deliver their load to competent cells of the immune system (7). This mini-review examines the main developments in various OMV technologies.

\section{OMV VACCINES AGAINST NEISSERIA MENINGITIDIS}

Meningococcal disease can occur rapidly following even mild symptoms and can result in fatality and disability. Thus, vaccination is seen as an essential strategy to prevent the rapid onset of infection. Current vaccines against N. meningitidis have been developed using the capsular polysaccharide of the pathogen and have been in use since the 1960s against serogroup A and C and 
since the 1980s against serogroups A, C, Y, and W (8). These structures are highly immunogenic and can be conjugated to carrier proteins to induce memory immune responses and immunogenicity in children younger than 2 years of age (9). However, polysaccharides from the N. meningitidis serogroup B (MenB) are low in immunogenicity and safety concerns have arisen due to potential risks of autoimmunity (3). Therefore, novel strategies, based on protein vaccines, have been developed to overcome this hurdle. The use of wild type OMV vaccines against MenB has been explored since the 1970s and public health interventions in countries such as Cuba, Norway, and New Zealand have proven the concept of their efficacy, with high effectiveness estimated in young and adults in the region where the circulating strain was the same as the vaccine strain (8). The Cuban VA-MENGOC$\mathrm{BC}^{\circledR}$ showed $83 \%$ effectiveness (over 16 months) in young and adults (10), the Norwegian MenBVac ${ }^{\circledR}$ showed $87 \%$ effectiveness (over 10 months) in young and adults (11), and MeNZB administered in New Zealand, showed 73\% effectiveness in the young and adults (12). In general, estimates of vaccine efficacy in children and infants are over $70 \%$, although the number of doses required may differ between each vaccine in order to keep protective immunity for a longer period of time, e.g., the Cuban vaccine is administered in two doses, whereas MenBVac ${ }^{\circledR}$ is given in three doses and $\mathrm{MeNZB}^{\circledR}$ in four doses (12). These vaccines are examples of parenteral licensed vaccines against meningococcal B disease (details summarized in Table $\mathbf{1}$ ).

The examples given above are wild type OMV vaccines, obtained using deoxycholate detergent extraction of the bacterial membranes. This method detoxifies and reduces the LPS content in vesicles to amounts proven to be safe by several millions of doses of OMV vaccines administered to humans $(10-12,14)$. All theses OMV vaccines have been demonstrated to be effective against the epidemic strain, although little or no effect has been found in infants when measuring effectiveness against heterologous strains by SBA (3), thus questioning their broad applicability against a range of circulating MenB strains. The immunodominant antigens in N. meningitidis OMV are porins PorA and PorB (14); there is a high variability between these proteins in strains of the same serogroup, therefore, the immune response to OMV is strain specific and some authors have proposed the concept of developing "tailor-made" vaccines against the circulating strain (3, 12). On the other hand, minor proteins in OMV, non-porins, are also responsible for the cross-protection level found in different clinical trials (3) and different strategies, such as the recent Novartis (Switzerland) Bexsero ${ }^{\circledR}$ vaccine (13) uses these minor proteins to construct a more universal vaccine. Several proteomic techniques have been developed to characterize protein antigens to aid the selection of appropriate strains and antigens to improve the extraction protocol (15). It is also known that detergent protocols may not be effective in extracting some important protein antigens such as Factor $\mathrm{H}$ binding protein (Fhbp), whereas other protocols (no detergents) permit extraction and inclusion of this antigen in the vesicles. Overall, it is very beneficial to remove endotoxins and allow inclusion of immunogenic antigens in OMV. The advantages of free detergent technologies or inclusion of recombinant proteins to dOMV are under evaluation in new candidates and licensed vaccines, respectively $(13,16)$.

The Bexsero ${ }^{\circledR}$ vaccine combines OMV that have been classically extracted by detergent and inclusion of recombinant antigens designed by reverse vaccinology (13). The recombinant antigens induce immune responses to a high number of serogroup B strains and the OMV potentiate the immune response to them. Novel strategies are envisaged to obtain OMV from recombinant $N$. meningitidis strains, where LPS has been genetically detoxified

Table 1 | OMV vaccines from $\boldsymbol{N}$. meningitidis serogroup B*.

\begin{tabular}{|c|c|c|c|}
\hline Vaccine name & Developmental history & Comments & Reference \\
\hline VA-MENGOC-BC ${ }^{\circledR}$ & $\begin{array}{l}\text { Developed at the Finlay Institute, Cuba, to } \\
\text { address an epidemic and tested between } 1987 \\
\text { and 1989. The strain type B:4:P1.19,15 was used }\end{array}$ & $\begin{array}{l}\text { Applied in the National Immunization Program of Cuba for more } \\
\text { than } 20 \text { years }\end{array}$ & $(3,10)$ \\
\hline MenBvac ${ }^{\circledR}$ & $\begin{array}{l}\text { Developed at the Norwegian Institute of Public } \\
\text { Health (NIPH) to address an epidemic and tested } \\
\text { between } 1988 \text { and } 1991 \text {. The production strain } \\
\text { was the 44/76-SL, type B:15:P1.7,16 }\end{array}$ & $\begin{array}{l}\text { Applied in a region of Normandy, France. This technology was } \\
\text { used to enable development of MeNZB }{ }^{\circledR} \text { and Bexsero }{ }^{\circledR} \text { vaccines }\end{array}$ & $(3,11)$ \\
\hline $\mathrm{MeNZB}^{\circledR}$ & $\begin{array}{l}\text { Developed against strain NZ 98/254 (strain type } \\
\text { B:4:P1.7-2) and used between } 2004 \text { and } 2008 . \\
\text { The project was a partnership between the WHO, } \\
\text { the New Zealand government, the University of } \\
\text { Auckland, NIPH, and Chiron }\end{array}$ & $\begin{array}{l}\text { Applied during epidemics in New Zealand. Significant partnership } \\
\text { development enabled a high number of clinical trials to be } \\
\text { carried out }\end{array}$ & $(8,12)$ \\
\hline Bexsero ${ }^{\circledR}$ & $\begin{array}{l}\text { Developed by Novartis, and designed to } \\
\text { provide broad-based protection. Recently } \\
\text { licensed by the European Medicines Agency } \\
\text { (www.ema.europa.eu) }\end{array}$ & $\begin{array}{l}\text { Combination of dOMV from strain NZ } 98 / 254 \text { with three } \\
\text { recombinant antigens, two of which are fusion proteins (targeting } \\
\text { five meningococcal proteins, total: the factor } \mathrm{H} \text {-binding protein, } \\
\text { neisserial adhesin A, and neisserial heparin-binding antigen) }\end{array}$ & $(13)$ \\
\hline
\end{tabular}

*The only OMV vaccines licensed to date. 
(lpx1-mutants), avoiding the need for detergent extraction. Furthermore, mutant strains with over-expressed protein vaccine antigens, like PorA and Fhbp, naturally inserted into the membranes have been constructed (16). Certainly, a high number of vaccine candidates with these characteristics will be seen in the next few years.

More recently, the Finlay Institute (Cuba) and the Norwegian Institute of Public Health (NIPH, Norway) have been working together to develop multivalent OMV vaccines against serogroups $\mathrm{A}\left(\mathrm{dOMV}_{\mathrm{A}}\right), \mathrm{W}\left(\mathrm{dOMV}_{\mathrm{W}}\right)$, and $\mathrm{X}\left(\mathrm{dOMV}_{\mathrm{X}}\right)(17,18)$. These serogroups represent the main cause of meningococcal disease in Africa (19). A Phase I clinical trial commenced at the end of 2013 to evaluate the safety of a bivalent candidate against serogroups A and $\mathrm{W}$ and the results are currently being examined (20). These dOMV were obtained using epidemic strains isolated in countries from the African "meningitis belt": $\mathrm{dOMV}_{\mathrm{A}}$ were developed from strain MK499/03, sequence type (ST) 5 clonal complex (cc) and $\mathrm{dOMV}_{\mathrm{W}}$ were developed from strain MK222/02, ST11 cc (21). All the strains belong to clonal complexes of serogroups that caused epidemics and outbreaks several years ago (22). On the other hand, new cases of meningococcal disease are produced by serogroup $\mathrm{X}$ in countries from the African meningitis belt (23). Based on previous experience with a combination of $\mathrm{dOMV}_{\mathrm{A}}$ and $\mathrm{dOMV}_{\mathrm{W}}$, both teams have begun research into a new combination including dOMV from meningococcal serogroup X strain BF 2/97 (cc.181) (17).

\section{OTHER APPLICATIONS}

Since MenB OMV have had significant exposure to humans in clinical trials, it is reasonable to assume that the safety and tolerability profile would encourage development of other applications. Thus, taking advantage of the immune stimulating molecules present in OMV. Since few adjuvants are licensed for human use, it was a reasonable concept to examine the potential of OMV for adjuvant activity. The adjuvant potential of MenB OMV $\left(\mathrm{OMV}_{\mathrm{B}}\right)$ have therefore been demonstrated with non-neisserial antigens (24), including with a herpes virus type 2 glycoprotein (gD2) (25), ovalbumin (24), and with allergens (17). With the latter application, a formulation of $\mathrm{dOMV}_{\mathrm{B}}$ containing mite allergens from Dermatophagoides siboney has been shown to be effective in a preclinical trial in controlling allergic reaction (26) and is currently undergoing a Phase I clinical trial (27). Another formulation, Protollin ${ }^{\mathrm{TM}}$ (Glaxo Smith Kline, GSK) has been developed that combines N. meningitidis outer membrane proteins (OMP) and LPS from Shigella flexneri. This formulation has been used as an intranasal adjuvant (28) and Phase I and II clinical trials have established that these vesicles are safe and well-tolerated (29). Additionally, a clinical trial of N. meningitidis OMP mixed only with influenza antigens (Proteasome-based influenza vaccine, GSK) demonstrated that the intranasal formulation was immunogenic and well-tolerated (30).

Overall, OMV developed from N. meningitidis have been successfully licensed or are undergoing clinical trial. Table 1 shows a summary of the most successful dOMV evaluated against meningitis. Other uses are also being found for these OMV and the following sections highlight the advances in R\&D of OMV derived from other bacteria that demonstrate the versatility of these structures.

\section{OMV VACCINES AGAINST BORDETELLA PERTUSSIS}

Whooping cough or pertussis is a highly contagious respiratory disease caused by Bordetella pertussis. Despite high vaccination coverage with whole cell or acellular vaccines, pertussis has reemerged not only in children, but also in adults, which can be an additional source of infection for infants $(31,32)$. Among the reasons offered to explain this resurgence is the waning of vaccineinduced immunity and the presumed low vaccine efficacy of acellular vaccines, which support the introduction of new vaccine candidates to confer a protective long-lasting immunity (33).

Pertussis proteoliposomes or OMV $\left(\mathrm{dOMV}_{\mathrm{BP}}\right)$ have been constructed from inactivated whole cells of B. pertussis strain 165 . Characterization studies have shown that these vesicles are composed of several immunogenic antigens including, pertussis toxin, fimbriae 3, and pertactin (34). Additionally, the $\mathrm{dOMV}_{\mathrm{BP}} \mathrm{vac}-$ cine was highly protective against the WHO strain 18323 in intracerebral and intranasal challenge models (34). Similarly, a group of researchers in Argentina have obtained nOMV $\mathrm{BP}_{\mathrm{BP}}$ using a detergent-free process with wild and mutant strains $(35,36)$; these candidate formulations were also protective when evaluated using an intranasal challenge model.

\section{OMV VACCINES AGAINST ENTERIC PATHOGENS}

Enteric infections induced by pathogens are one of the main causes of death all over the world (6). The main bacterial agents are Vibrio cholerae, Salmonella spp., Shigella spp., and Escherichia coli. $V$. cholerae $\mathrm{O} 1$ proteoliposomes were the first vesicles $\left(\mathrm{OMV}_{\mathrm{C}}\right)$ obtained at the Finlay Institute from enteric pathogens. Figure 1 shows a micrograph of $\mathrm{OMV}_{\mathrm{C}}$ from Perez et al. which demonstrated that these vesicles induced an antibody response with vibriocidal activity when administered via the nasal route (37). An $O M V_{C}$ extraction process was developed with sodium dodecyl sulfate (SDS) detergent to achieve maximum recovery of LPS from the bacteria. Protein antigens with vaccine potential, such as OmpU and MSHA, were also found in $\mathrm{OMV}_{\mathrm{C}}$ (37). In an alternative approach, Schild et al. obtained $\mathrm{nOMV}_{\mathrm{C}}$ using a detergent-free method and demonstrated that intranasal and oral administration of these vesicles were immunogenic and protective in a model where the offspring of immunized female mice were infection challenged (38).

Selection of the detergent can be a critical step for extracting immunogenic OMV. LPS is the main antigen of enteric pathogens, but it is also a potent toxin with differing potency in Gram negative pathogens (39); therefore, detergent and purification steps, may differ according to the antigen that needs to be expressed or removed from the vesicles. Recently, the production of OMV obtained by detergent-free protocols has gained interest, because the generation of mutant strains, hyper expressing important protein antigens, and detoxified molecules may improve the yield, immunogenicity, and safety profile of the $\operatorname{OMV}(5,16)$.

Several OMV extracts from different enteric pathogens have been evaluated at the Finlay Institute. A multivalent formulation that contained dOMV from $V$. cholerae, S. enteritidis, $S$. typhimurium, Shigella sonnei, and S. flexneri elicited high IgG (serum) and IgA (saliva) levels in mice and rats immunized orally (40). Additionally, OMV from enteropathogenic (EPEC) and enterotoxigenic (ETEC) strains of E. coli were evaluated in mice showing high specific antibody responses and heterologous 


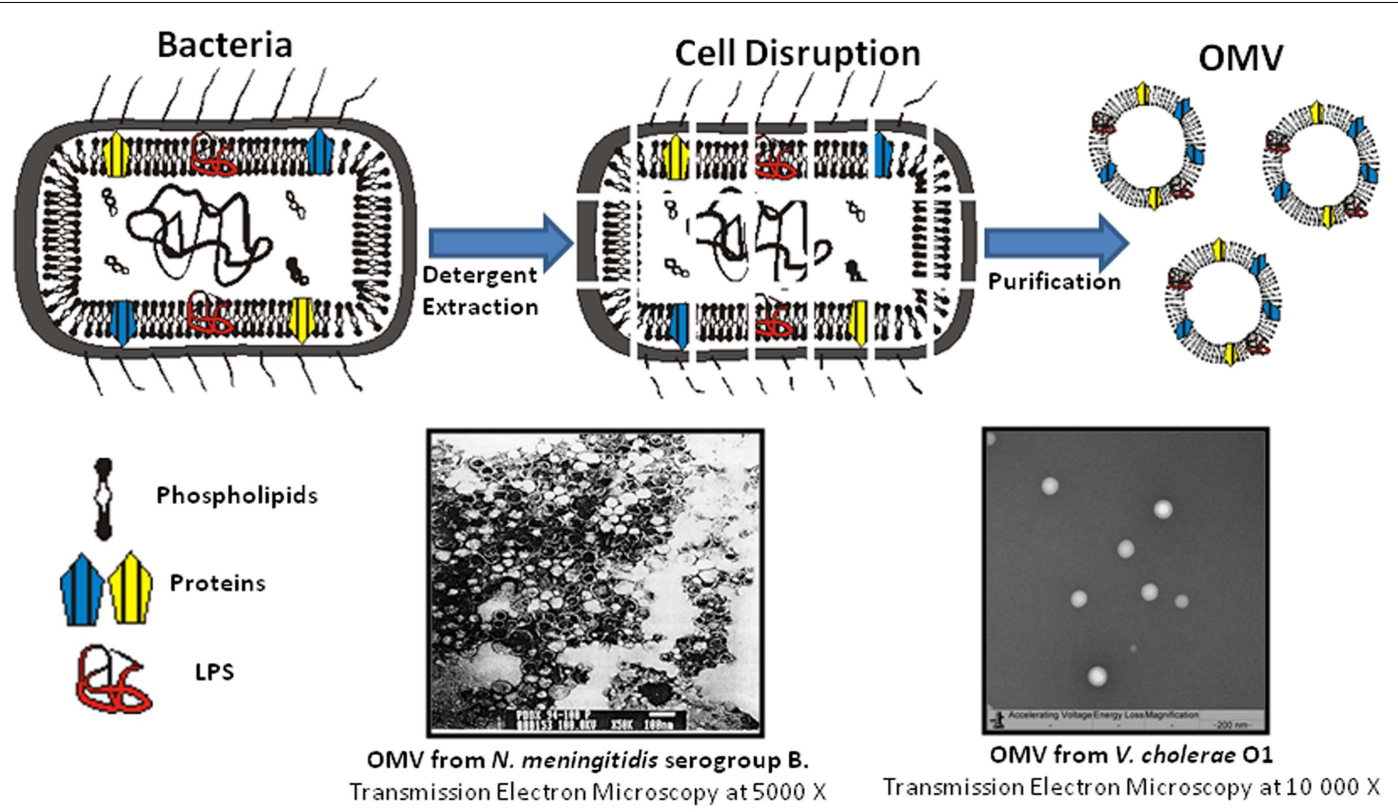

FIGURE 1 | Schematic representation of the dOMV extraction process and two micrographs of OMV obtained using this technology with two different detergents: OMV from $N$. meningitidis serogroup $B$ extracted with deoxycholate $(10)$ and
OMV from $\boldsymbol{V}$. cholerae 01 extracted with sodium dodecyl sulfate (37). OMV have a similar size and vesicle like structure. Differences observed between micrographs are mainly due to changes in magnification and stains used. cross-reactivity between them (41). Camacho et al. also demonstrated the potential of a mucosal candidate vaccine based on nOMV from S. flexneri (42).

Acevedo et al. demonstrated that a combination of $\mathrm{dOMV}_{\mathrm{C}}$ with polysaccharide $\mathrm{Vi}(\mathrm{PsVi}$ ) from $S$. typhi, administrated via the nasal route, can induce immune responses at mucosal level, but also results in systemic specific IgG anti-PsVi responses as high as the parenteral PsVi vaccine vax-TyVi ${ }^{\circledR}$ (Finlay Institute) (43). The potential use of combinations of different OMV or their capacity to be combined with antigens may have important impact in the future in the development of vaccines against enteric pathogens.

\section{OMV VACCINES AGAINST TUBERCULOSIS}

Mycobacterial extracts have been widely used in vaccine developments, including the use of Freund's complete adjuvant (FCA), which contains fragments from the mycobacteria. In particular, the mycobacterial cell wall contains a variety of antigenic and immunostimulatory molecules, such as peptidoglycan, arabinogalactan, mycolic acids, proteins, phosphatidylinositol mannosides, tiocerol, lipomanann, and lipoarabinomann, which activate dendritic cells via mannose and NOD2 receptors, among others $(44,45)$. All these components are important molecular effectors involved in the infection process and have been reported to induce protective responses in mice against TB $(46,47)$.

New formulations, which are safer than FCA, but still immunogenic, are also under evaluation. For example, RUTI consists of a Mycobacterium tuberculosis (MTB) protein extract and lipids, which are delivered in liposomes (48). Preclinical experiments show that RUTI is able to induce marked accumulation of antigen specific IFN- $\gamma$-producing CD4+ and CD $8+$ T cells, whereas BCG increases only the recruitment of CD4+ T cells. A short treatment regimen with chemotherapy (isoniazid) and RUTI is under evaluation in clinical trials. The reduction time in treatment as well as increased efficacy in chemotherapy will impact on the regression of the disease as well as the reduction of drug resistant MTB strains (48). Another, mycobacterial derivative with adjuvant and vaccine potential is the CAF01 formulation (49). The mycobacterium cord factor trehalose-6,6-dimycolate and its synthetic analog trehalose-6,6-dibehenate (TDB) are potent glycolipid immune stimulators that are recognized by a C-type lectin Mincle receptor (50). This signal activates dendritic cells, leading to cytokine production and up-regulation of co-stimulatory molecules (50). Incorporation of TDB in cationic liposomes (CAF01) together with the recombinant fusion protein Ag85B/ESAT-6 is a promising strategy against TB, developed by the Staten Serum Institute (Copenhagen, Denmark) (51).

dOMV derived from non-pathogenic mycobacteria have also been obtained. M. smegmatis and BCG have high levels of genomic and antigenic homology with MTB (52). Therefore, it is not surprising that proteoliposomes (dOMV) derived from both mycobacteria have induced cross-reactive immune responses against MTB antigens at cellular and humoral levels in mice $(52,53)$. Recent results have demonstrated that these candidates are as protective as BCG in challenge experiments conducted in mice (54).

\section{CONCLUSION}

Outer membrane vesicles are very complex supramolecular structures. They contain immune stimulators (e.g., LPS, proteins, and DNA) and antigenic molecules that can be delivered to immune 
competent cells of the immune system to trigger maturation as well as activation signals. Therefore, OMV have an intrinsic adjuvant effect over loaded antigens from bacteria, but also over heterologous antigens that can be incorporated or combined in a single formulation. Altogether, the versatility to enable administration via the mucosal or parenteral route offers significant choice. The adjuvant potential and increased knowledge in the design of OMV over the last few decades will also enable the future development of the next generation of novel vaccine formulations.

\section{REFERENCES}

1. Lowell GH, Ripley BW, Smith LF, Wirtz RA, Zollinger WD, Hockmeyer WT. Proteasome-lipopeptide vaccines: enhancement of immunogenicity for malaria CS peptides. Science (1988) 240:800-2. doi:10.1126/science.2452484

2. Mesa C, de Leon J, Fernandez LE. Very small size proteoliposomes derived from Neisseria meningitidis: an effective adjuvant for generation of CTL responses to peptide and protein antigens. Vaccine (2006) 24(14):2692-9. doi:10.1016/j. vaccine.2005.01.114

3. Holst JD, Martin R, Campa C, Oster P, O'Hallahan J, Rosenqvist E. Properties and clinical performance of vaccines containing outer membrane vesicles from Neisseria meningitidis. Vaccine (2009) 30S:B10-7. doi:10.1016/j.vaccine.2009.04.071

4. Stephens DS. Biology and pathogenesis of the evolutionarily successful, obligate human bacterium Neisseria meningitidis. Vaccine (2009) 27S:B71-7. doi:10. 1016/j.vaccine.2009.04.070

5. Van der Ley P, van den Dobbelsteen G. Next generation outer membrane vesicle vaccines against Neisseria meningitidis based on nontoxic LPS mutants. Hum $\operatorname{Vaccin}(2011)$ 7(8):886-90. doi:10.4161/hv.7.8.16086

6. WHO. State of the Art of New Vaccine Research and Development. (2005). Available from: <http://www.who.int/vaccine_research/documents/stateoftheart/ en/index.html $>$

7. Rodriguez T, Perez O, Ugrinovic S, Bracho G, Mastroeni P. Bacterial derived proteoliposome as ideal delivery system and cellular adjuvant. Vaccine (2006) 24(Suppl 2):24. doi:10.1016/j.vaccine.2005.01.106

8. Holst J, Oster P, Arnold R, Tatley MV, Næss LM, Aaberge IS, et al. Vaccines against meningococcal serogroup $B$ disease containing outer membrane vesicles (OMV): lessons from past programs and implications for the future. Hum Vaccin Immunother (2013) 9(6):1241-53. doi:10.4161/hv.24129

9. Miller JM, Mesaros N, Van Der Wielen M, Baine Y. Conjugate meningococcal vaccines development: GSK biologicals experience. Adv Prev Med (2011) 846756:1-17. doi:10.4061/2011/846756

10. Sierra G, Campa HC, Varcacel NM, Izquierdo PL, Sotolongo PF, Garcia L. Vaccine against group B Neisseria meningitidis: protection trial and mass vaccination results in Cuba. NIPH Ann (1991) 14:195-210.

11. Rosenqvist E, Høiby EA, Wedege E, Bryn K, Kolberg J. Human antibody responses to meningococcal outer membrane antigens after three doses of the Norwegian group B meningococcal vaccine. Infect Immun (1995) 63:4642-52.

12. Arnold R, Galloway Y, McNicholas A, O’Hallahan J. Effectiveness of a vaccination programme for an epidemic of meningococcal B in New Zealand. Vaccine (2011) 29:7100-6. doi:10.1016/j.vaccine.2011.06.120

13. Bai X, Findlow J, Borrow R. Recombinant protein meningococcal serogroup B vaccine combined with outer membrane vesicles. Expert Opin Biol Ther (2011) 11(7):969-85. doi:10.1517/14712598.2011.585965

14. Feavers IM, Pizza M. Meningococcal protein antigens and vaccines. Vaccine (2009) 27S:B42-50. doi:10.1016/j.vaccine.2009.05.001

15. Williams JN, Skipp PJ, Humphries HE, Christodoulides M, O'Connor D, Heckels JE. Proteomic analysis of outer membrane vesicles from wild type serogroup B Neisseria meningitidis and a lipopolysaccharide-deficient mutant. Infect Immun (2007) 75(3):1364-72. doi:10.1128/IAI.01424-06

16. Van de Waterbeemd B, Streefland M, van der Ley P, Zomer B, van Dijken H, Martens D, et al. Improved OMV vaccine against Neisseria meningitidis using genetically engineered strains and a detergent-free purification process. Vaccine (2010) 28:4810-6. doi:10.1016/j.vaccine.2010.04.082

17. Norheim G, Tunheim G, Naess LM, Bolstad K, Fjeldheim AK, Garcia L, et al. A trivalent outer membrane vesicle (OMV) vaccine against serogroup $\mathrm{A}, \mathrm{W}-135$ and X meningococcal disease. XVIIIth International Pathogenic Neisseria Conference. Würzburg: Conventus Congress Management \& Marketing GmbH (2012).

18. Tunheim G, Arnemo M, Næss LM, Fjeldheim AK, Nome L, Bolstad K, et al. Preclinical immunogenicity and functional activity studies of an A+W meningococcal outer membrane vesicle (OMV) vaccine and comparisons with existing meningococcal conjugate- and polysaccharide vaccines. Vaccine (2013) 31:6097-106. doi:10.1016/j.vaccine.2013.09.044

19. Caugant DA, Kristiansen PA, Wang X, Mayer LW, Taha MK, Ouédraogo $\mathrm{R}$, et al. Molecular characterization of invasive meningococcal isolates from countries in the African meningitis belt before introduction of a serogroup A conjugate vaccine. PLoS One (2012) 7:e46019. doi:10.1371/journal.pone. 0046019

20. Clinical trial of bivalent antimeningococcal vaccine candidate based on outer membrane vesicle AW135/Ensayo clinico con el candidato vacunal bivalente antimeningococico AW135 de Vesiculas de Membrana Externa. RPCEC (Cuban Public Register of Clinical Trials). Finlay Institute (2013). Available from: http: //rpcec.sld.cu/ensayos/RPCEC00000160-Sp

21. Norheim G, Tunheim G, Næss LM, Kristiansen PA, Caugant DA, Rosenqvist E. An outer membrane vesicle vaccine for prevention of serogroup A and W-135 meningococcal disease in the African meningitis belt. Scand J Immunol (2012) 76(2):99-107. doi:10.1111/j.1365-3083.2012.02709.x

22. Caugant DA, Nicolas P. Molecular surveillance of meningococcal meningitis in Africa. Vaccine (2007) 25(Suppl 1):A8-11. doi:10.1016/j.vaccine.2007.04.033

23. Xie O, Pollard AJ, Mueller JE, Norheim G. Emergence of serogroup X meningococcal disease in Africa: need for a vaccine. Vaccine (2013) 31:2852-61. doi:10.1016/j.vaccine.2013.04.036

24. Perez O, Lastre M, Cabrera O, del Campo J, Bracho G, Cuello M, et al. New vaccines require potent adjuvants like AFPL1 and AFCol. Scand J Immunol (2007) 66(2-3):271-7. doi:10.1111/j.1365-3083.2007.01981.x

25. Del Campo J, Lindqvist M, Cuello M, Bäckström M, Cabrerra O, Persson J, et al. Intranasal immunization with a proteoliposome-derived cochleate containing recombinant gD protein confers protective immunity against genital herpes in mice. Vaccine (2010) 28:1193-200. doi:10.1016/j.vaccine.2009.11.035

26. Lastre M, Perez O, Labrada A, Bidot I, Perez J, Bracho G, et al. Bacterial derived proteoliposome for allergy vaccines. Vaccine (2006) 24(Suppl 2):S2-34. doi:10.1016/j.vaccine.2005.01.110

27. Subcutaneous immunotherapy with PROLINEM -Asthma- Adults-Fase I. RPCEC (Cuban Public Register of Clinical Trials). National Center of Bioproducts (2013). Available from: http://rpcec.sld.cu/trials/RPCEC00000139-En

28. Jones T, Cyr S, Allard F, Bellerose N, Lowel GH, Burt DS. Protollin ${ }^{\mathrm{TM}}$ : a novel adjuvant for intranasal vaccines. Vaccine (2004) 22:3691-7. doi:10.1016/j.vaccine. 2004.03.035

29. Fries LF, Montemarano AD, Mallett CP, Taylor DN, Hale TL, Lowell GH. Safety and immunogenicity of a proteasome-Shigella flexneri 2 a lipopolysaccharide vaccine administered intranasally to healthy adults. Infect Immun (2001) 69:4545-53. doi:10.1128/IAI.69.7.4545-4553.2001

30. Burt D, Mallett C, Plante M, Zimmermann J, Torossian K, Fries L. Proteasome-adjuvanted intranasal influenza vaccines: advantages, progress and future considerations. Expert Rev Vaccines (2011) 10(3):365-75. doi:10.1586/ erv. 10.172

31. Rohania P, Draked JM. The decline and resurgence of pertussis in the US. Epidemics (2011) 3:183-8. doi:10.1016/j.epidem.2011.10.001

32. Cherry JD. Epidemic pertussis in 2012. The resurgence of a vaccine-preventable disease. N Engl J Med (2012) 367:785-7. doi:10.1056/NEJMp1209051

33. Witt MA, Arias L, Katz PH, Truong ET, Witt DJ. Reduced risk of pertussis among persons ever vaccinated with whole cell pertussis vaccine compared to recipients of acellular pertussis vaccines in a large US cohort. Clin Infect Dis (2013) 56:1248. doi:10.1093/cid/cit046

34. Fernández S, Fajardo EM, Mandiarote A, Año G, Padrón MA, Acosta M, et al. A proteoliposome formulation derived from Bordetella pertussis induces protection in two murine challenge models. BMC Immunol (2013) 14(Suppl 1):S8. doi:10.1186/1471-2172-14-S1-S8

35. Asensio CJ, Gaillard ME, Moreno G, Bottero D, Zurita E, Rumbo M, et al. Outer membrane vesicles obtained from Bordetella pertussis Tohama expressing the lipid A deacylase PagL as a novel acellular vaccine candidate. Vaccine (2011) 29(8):1649-56. doi:10.1016/j.vaccine.2010.12.068 
36. Roberts R, Moreno G, Bottero D, Gaillard ME, Fingermann M, Graieb A, et al. Outer membrane vesicles as acellular vaccine against pertussis. Vaccine (2008) 26(36):4639-46. doi:10.1016/j.vaccine.2008.07.004

37. Perez JL, Acevedo R, Callico A, Fernandez Y, Cedre B, Ano G, et al. A proteoliposome based formulation administered by the nasal route produces vibriocidal antibodies against El Tor Ogawa Vibrio cholerae O1 in BALB/c mice. Vaccine (2009) 27(2):205-12. doi:10.1016/j.vaccine.2008.10.052

38. Schild S, Nelson EJ, Camilli A. Immunization with Vibrio cholerae outer membrane vesicles induces protective immunity in mice. Infect Immun (2008) 76(1):4554-63. doi:10.1128/IAI.00532-08

39. Raetz CRH, Whitfield C. Lipopolysaccharide endotoxins. Annu Rev Biochem (2002) 71:635-700. doi:10.1146/annurev.biochem.71.110601.135414

40. Pérez JL, Callicó A, Fernández S, Reyes G, Cabreras R, Acosta M, et al. Preliminary characterization of an oral multivalent vaccine candidate against CholeraShigella-Salmonella. Vaccimonitor (2009) 18(1):7.

41. Callicó A, Reyes G, Fernández S, Cabrera R, Acosta M, Aranguren Y, et al. Proteoliposomes derived from Escherichia coli induced systemic and mucosal response. Vaccimonitor (2010) 19(1):32.

42. Camacho AI, de Souza J, Sánchez-Gómez S, Pardo-Ros M, Irache JM, Gamazo C. Mucosal immunization with Shigella flexneri outer membrane vesicles induced protection in mice. Vaccine (2011) 29:8222-9. doi:10.1016/j.vaccine.2011.08.121

43. Acevedo R, Callicó A, Aranguren Y, Zayas C, Valdés Y, Pérez O, et al. Immune adjuvant effect of $V$. cholerae $\mathrm{O} 1$ derived Proteoliposome coadministered by intranasal route with Vi polysaccharide from Salmonella Typhi. BMC Immunol (2013) 14(Suppl 1):S10. doi:10.1186/1471-2172-14-S1-S10

44. Brennan PJ. Structure, function, and biogenesis of the cell wall of Mycobacterium tuberculosis. Tuberculosis (2003) 83(1):91-7. doi:10.1016/S14729792(02)00089-6

45. Coulombe F, Divangahi M, Veyrier F, Léséleuc L, Gleason JL, Yang Y, et al. Increased NOD2-mediated recognition of N-glycolyl muramyl dipeptide. J Exp Med (2009) 206(8):1709. doi:10.1084/jem.20081779

46. Jeon BY, Kim HJ, Jo EK, Park JK, Paik TH, Kim SJ, et al. Protection of mice against Mycobacterium tuberculosis infection by immunization with aqueous fraction of triton X-100-soluble cell proteins. Scand J Inmunol (2008) 67(1):18-23. doi:10.1111/j.1365-3083.2007.02031.x

47. Hamasur B, Haile M, Pawlowski A, Schröder U, Williams A, Hatch G, et al. Mycobacterium tuberculosis arabinomannan-protein conjugates protect against tuberculosis. Vaccine (2003) 21:4081-93. doi:10.1016/S0264-410X(03)00274-3

48. Cardona PJ. RUTI: a new chance to shorten the treatment of latent tuberculosis infection. Tuberculosis (Edinb) (2006) 86(3-4):273-89. doi:10.1016/j.tube.2006. 01.024
49. Christensen D, Agger EM, Andreasen LV, Kirby D, Andersen P, Perrie Y. Liposome-based cationic adjuvant formulations (CAF): past, present, and future. J Liposome Res (2009) 19(1):2-11. doi:10.1080/08982100902726820

50. Agger EM, Rosenkrands I, Hansen J, Brahimi K, Vandahl BS, Aagaard C, et al. Cationic liposomes formulated with synthetic mycobacterial cord factor (CAF01): a versatile adjuvant for vaccines with different immunological requirements. PLoS One (2008) 3(9):e3116. doi:10.1371/journal.pone.0003116

51. Barker LF, Chen V, Meyer D, Rosenstein PK, Brennan MJ. New tuberculosis vaccines: what is in the pipeline? In: Acosta A, Nor NM, Sarmiento ME editors. The Art and Science of Tuberculosis Vaccine Development. Oxford: Oxford University Press (2010).

52. Reyes F, Tirado Y, Puig A, Borrero R, Reyes G, Fernández S, et al. Immunogenicity and cross-reactivity against Mycobacterium tuberculosis of proteoliposomes derived from Mycobacterium bovis BCG. BMC Immunol (2013) 14(Suppl 1):S7. doi:10.1186/1471-2172-14-S1-S7

53. Rodriguez L, Tirado Y, Reyes F, Puig A, Kadir R, Borrero R, et al. Proteoliposomes from Mycobacterium smegmatis induce immune cross-reactivity against Mycobacterium tuberculosis antigens in mice. Vaccine (2011) 29(37):6236-41. doi:10.1016/j.vaccine.2011.06.077

54. Acosta A, Kadir R, Ahmad F, Puig A, Borrero R, Garcia M, et al. Development of experimental strategies for the prophylaxis and treatment of tuberculosis. Latinfarma. Havana: (2013).

Conflict of Interest Statement: The authors declare that the research was conducted in the absence of any commercial or financial relationships that could be construed as a potential conflict of interest.

Received: 29 July 2013; accepted: 09 March 2014; published online: 24 March 2014. Citation: Acevedo R, Fernández S, Zayas C, Acosta A, Sarmiento ME, Ferro VA, Rosenquist E, Campa C, Cardoso D, Garcia L and Perez JL (2014) Bacterial outer membrane vesicles and vaccine applications. Front. Immunol. 5:121. doi: 10.3389/fimmu.2014.00121

This article was submitted to Immunotherapies and Vaccines, a section of the journal Frontiers in Immunology.

Copyright (c) 2014 Acevedo, Fernández, Zayas, Acosta, Sarmiento, Ferro, Rosenqvist, Campa, Cardoso, Garcia and Perez. This is an open-access article distributed under the terms of the Creative Commons Attribution License (CC BY). The use, distribution or reproduction in other forums is permitted, provided the original author(s) or licensor are credited and that the original publication in this journal is cited, in accordance with accepted academic practice. No use, distribution or reproduction is permitted which does not comply with these terms. 